\title{
ПОЛИТИКА ПРОТИВОДЕЙСТВИЯ ФИНАНСИРОВАНИЮ ТЕРРОРИЗМА: ОПРЕДЕЛЕНИЕ И УГРОЗЫ В УСЛОВИЯХ РАЗВИТИЯ РЫНКА ИСКУССТВЕННОГО ИНТЕЛЛЕКТА
}

\author{
(C) 2019 Чернов Сергей Борисович \\ кандидат экономических наук, доцент кафедры экономической теории и мировой экономики \\ Государственный университет управления, Россия, Москва \\ Email: chernov_s_b@mail.ru
}

Дана современная трактовка политики противодействия финансированию терроризма. Рассмотрены и систематизированы виды экономической политики противодействия финансированию терроризма. Установлена связь между развитием рынка искусственного интеллекта и угрозами для противодействия финансированию терроризма. Обсуждаются функции государства в области противодействия финансированию терроризма.

Ключевые слова: политика противодействия финансированию терроризма, теневая экономика, криминальный капитал, криптовалюта, угрозы.

Стратегия устойчивого поступательного развития экономики России предполагает решение ряда крупных масштабных задач, в том числе устранение условий возникновения террористических угроз поступательному социальноэкономическому развитию Российской Федерации. В настоящее время Россия, являясь одной из самых богатых стран в мире по ресурсному потенциалу, не является преуспевающей по уровню жизни граждан, другим социальноэкономическим показателям. В экономике России продолжают доминировать такие негативные факторы, как: зависимость от конъюнктуры мировых цен на товары сырьевого экспорта; низкий внутренний спрос и неспособность российской промышленности его обеспечить; слабая финансовая система и отсутствие в экономике «длинных» денег; низкая техническая оснащенность организаций реального сектора экономики; значительная доля теневого сектора экономики. При этом энергозатраты в российской экономике, прежде всего в силу климатических условий, намного выше, чем в других странах. Таким образом, российский производитель будет проигрывать зарубежному конкуренту, если последовать призывам установить в России мировые цены на энергоресурсы.

В новой стратегии национальной безопасности Российской Федерации в качестве ключевых угроз выделяются разведывательные и иные виды деятельности специальных служб и организаций иностранных государств, террористических и экстремистских организаций, преступ- ных организаций и группировок, радикальных общественных объединений [1]. В условиях объявления санкций рядом иностранных государств Российской Федерации, нежелающих допустить возвращение России в число лидеров мирового рынка, можно с большой уверенностью ожидать возрастания угроз проведения подрывных специальных операций иностранных спецслужб, поощрение ими экстремистских, террористических организаций и радикальных общественных объединений. Формирование нестабильности и тревожности в обществе может привести росту социальной напряженности, обострению межнациональных отношений и снижению инвестиционной активности.

Организованный экстремизм и терроризм не могут существовать без финансовых источников. Для осуществления террористических актов террористы несут материальные затраты, оплачивают труд наемников, закупают оборудование, транспорт, средства связи, топливо, подкупают должностных лиц государственных и муниципальных органов власти, осуществляют другие платежи. Таким образом, финансирование терроризма - это какие-либо действия, совершенные с целью финансового или материального обеспечения: отдельного террориста; создания и развития террористической группы (организации); вовлечения в террористическую деятельность сторонних лиц; публичных призывов к совершению террористического акта; содействия совершению террористического акта; подготовки и проведения террористического 
акта; обналичивания денежных средств для их использования в финансировании террористической деятельности; легализации грязных денег и другого имущества, полученных в результате осуществления террористической деятельности.

Для недопущения возникновения и развития террористических организаций государству необходимо проводить антитеррористическую экономическую политику, под которой понимается комплекс экономических мер, нацеленных на сокращение деятельности субъектов теневой экономики и предотвращение возможности легализации полученных доходов от террористической деятельности [2]. В зависимости от содержания можно выделить различные формы данной политики: запретительная; профилактическая; легализующая. Запретительная экономическая политика государства имеет целью формирование труднопреодолимых барьеров на путях легализации теневых доходов и проникновения представителей теневого капитала в законодательные и исполнительные органы государственной и муниципальной власти и в средства массовой информации. В этих целях и в соответствии с Федеральным законом от 07.08.2001 N115-Ф3 (ред. от 03.07.2019) «О противодействии легализации (отмыванию) доходов, полученных преступным путем, и финансированию терроризма» осуществляется замораживание средств и имущества подозреваемых в причастности к террористической деятельности организаций или физических лиц [3].

В настоящее время в соответствии с Федеральным законом от 06.03.2006 N35-Ф3 (ред. от 18.04.2018, с изм. от 29.03.2019) «О противодействии терроризму» лицам, оказывающим содействие в выявлении, предупреждении, пресечении, раскрытии и расследовании террористического акта, выявлении и задержании лиц, подготавливающих, совершающих или совершивших такой акт, из средств федерального бюджета может выплачиваться денежное вознаграждение [4]. Источники финансирования выплат денежного вознаграждения устанавливаются Правительством Российской Федерации. Размер, основания и порядок выплат денежного вознаграждения определяются федеральным органом исполнительной власти в области обеспечения безопасности. Предлагается сделать такие выплаты обязательными.

K запретительной политике также следует относить меры по недопущению формирования теневого бухгалтерского учета. Под последним понимается система сбора, регистрации и обработки информации об используемом в теневой экономике имуществе, возникающих обязательствах, проводимых теневых хозяйственных операциях и возникающих теневых доходах. Скрываемая информация накапливается в денежном и натуральном выражении работниками теневой бухгалтерии путем частичного или полного регистрирования вышеназванных объектов учета, так как в большинстве случаев теневой предприниматель сознательно отказывается от полной регистрации в целях вовлечения в теневую экономическую деятельность наемных работников либо из-за скрытого характера теневой экономики полная регистрация невозможна или не ведется; прерывистого ведения учета, осуществляемого на основных стадиях движения теневого капитала (формирование капитала, закупка, производство, реализация), с момента начала теневой экономической деятельности до ее завершения. Скрытый характер работы, как правило, не позволяет организовать непрерывность учета имущества, обязательств, хозяйственных операций и доходов.

Для регистрации фактов теневой хозяйственной активности применяются разнообразные формы, заполняемые в неучтенных официально журналах, блокнотах, листах, карточках или электронных документах. Не редки случаи, когда в фиктивной экономике для регистрации теневой деятельности используются официальные документы, на которых карандашом (реже чернилами) делаются особые пометки. При незначительных масштабах ведения противоправной экономической деятельности и в целях ее конспирации используемое в теневой экономике имущество, возникшие и незарегистрированные установленным образом обязательства и осуществляемые теневые хозяйственные операции могут не отражаться ни только в официальном бухгалтерском учете, но и на бумажных и электронных носителях, используемых в теневой бухгалтерии. Поэтому в ходе расследования теневых хозяйственных операций выявленные в ходе ревизии, аудиторских и других проверок материалы теневого бухгалтерского учета необходимо сопоставлять с документами первичного учета, учетными регистрами и бухгалтерской (финансовой) отчетностью проверяемых организаций. 
Исходя из вышеуказанного, а также учитывая возможное коррупционное прикрытие террористической деятельности в качестве запретительных мер экономической политики противодействия финансированию терроризма предлагается: выявлять, раскрывать и расследовать в первоочередном порядке коррупционные преступления, совершенные в крупном и особо крупном размере; ограничивать не только сумму оплаты наличными по договору между организациями, но и число таких сделок за одни сутки; конкретизировать ответственность учредителей организации за формирование теневого бухгалтерского учета.

Под профилактикой терроризма понимается деятельность по предупреждению терроризма, в том числе по выявлению и последующему устранению причин и условий, способствующих совершению террористических актов. Профилактическая экономическая политика включает в себя методы, обеспечивающие стабильное развитие экономической системы. Снижение курса национальной валюты, инфляция и экономический кризис (стагфляция) выступают ускорителями формирования и увеличения теневого капитала и увеличивают риск использования теневых доходов для финансирования террористической деятельности. Например, стабильность рубля в условиях его резкого обесценения может достигаться, наряду с другими факторами, денежной рестрикцией с одновременным введением обязательной продажи экспортерами части своей валютной выручки и расширением государственных программ поддержки реального сектора национальной экономики. Государственная помощь должна оказываться только тем организациям, которые разработали и внедряют программы сокращения издержек по выпуску продукцию и оказываемым услугам, а также тем организациям, которые участвуют в социальной адаптации лиц, раннее осужденных за преступления террористической направленности.

Для профилактики теневой экономической деятельности предлагается:

- сглаживать значительную социальноэкономическую дифференциацию населения по уровню доходов путем принятия ступенчатой шкалы налоговых ставок налога на доходы физических лиц;

- совершенствовать качественную подготовку специалистов, способных работать в но- вых условиях хозяйствования;

- вернуть государству основную роль в выполнении социальных программ в области пенсионного и медицинского обслуживания;

- развивать творчество масс путем законодательного закрепления обязательного создания профсоюзов в трудовых коллективах и их участия в управлении организациями;

- обеспечивать реализацию социальных гарантий лицам, работающим по найму;

- использовать средства социальной рекламы, литературы и искусства;

- формализовать деятельность должностных лиц путем четкой регламентации их действий;

- развивать электронный документооборот;

- добиваться неукоснительной ответственности должностных лиц за нарушение конституционных прав и свобод граждан;

- совершенствовать механизм исполнения судебных решений (определений).

Особое значение в профилактической экономической политике должно быть отведено социальной адаптации лиц, раннее осужденных за преступления террористической направленности, и созданию рабочих мест в трудоизбыточных регионах с высоким риском возникновения экстремистской и террористической деятельности. Нельзя допускать снижение социальной защищенности российских трудящихся под флагом оптимизации бюджетных расходов. Повышение пенсионного возраста, отказ в индексации пенсий работающих пенсионеров являются побудительными мотивами к вовлечению в теневую экономическую деятельность новых участников рынка труда.

Целесообразно доход любого налогоплательщика ниже прожиточного минимума освобождать от налогообложения. Неоправданно высокие доходы должны облагаться налогами по повышенной ставке в условиях введения прогрессивного налогообложения. Тем самым будут созданы автоматические стабилизаторы экономики и восстановлено равенство в налоговой нагрузке на различных налогоплательщиков. В то же время представители крупного капитала должны осознать свою социальную ответственность за развитие общества и государства, научиться извлекать положительный опыт из исторического прошлого.

Используя телевидение, радио и Интернет 
как самые выразительные, доступные и популярные средства массовых коммуникаций и художественных средств, государство имеет возможность воздействовать на общество, формируя негативное отношение к коррупционерам, дельцам теневой экономики и субъектам террористической деятельности. Механизмы использования средств массовой информации в целях внедрения идеологии, пропаганды и агитации были хорошо отработаны в Советском Союзе и могут использоваться в современной профилактической экономической политике.

Посредствам телевидения, радио, системы Интернета и социальных сетей государство имеет возможность повышать не только общий уровень культуры и образования населения, но и формировать экономико-правовую культуру поведения граждан, доводить до них правовые и безопасные правила поведения при контакте с коррумпированными государственными и муниципальными служащими, недобросовестными представителями теневых предпринимательских структур и участниками террористических и экстремистских организаций.

Изучая имеющийся зарубежный опыт по работе с общественным мнением, необходимо его использовать в целях создания положительного образа предпринимателя, любого гражданина, стремящегося не столько к личной наживе, сколько к социально значимым для общества целям. Также следует обратить внимание на значительную роль телевидения, радио, Интернета и социальных сетей в формировании положительного облика сотрудников правоохранительных органов. Необходимо восстанавливать в обществе качественный уровень доверия к сотрудникам правоохранительных органов, популяризировать их профессии и формировать нетерпимое отношение к коррупционной, экстремистской и террористической деятельности.

Легализация неофициальной экономики должна строиться на упрощении системы регистрации обществ с ограниченной ответственностью и предпринимателей, функционирующих без образования юридического лица. В этих целях предлагается:

- использовать преимущественно уведомительный порядок регистрации обществ с ограниченной ответственностью, а также индивидуальных предпринимателей;

- шире использовать упрощенную систему учета;
- увеличить сроки представления отчетности (один раз в полгода) для субъектов малого предпринимательства, если они не подпадают под требования проведения обязательного аудита;

- оптимизировать налоговую нагрузку предпринимательской деятельности и снизить ее в аграрном секторе экономики;

- развивать безвозмездное налоговое и другое консультирование граждан в области предпринимательства и социальной защиты трудящихся, например, на сайтах федеральных министерств, служб и муниципальных органов власти.

Анализируя виды и методы антитеррористической экономической политики государства необходимо отметить, что они зависят от формы теневой экономики, в которой могут формироваться финансовые источники террористической деятельности. Запретительная и профилактическая экономическая политика должна применяться против участников черной и фиктивной экономики. В целях уменьшения неофициальной экономики в дополнении к запретительной и профилактической экономической политике целесообразно применять широкий комплекс мер по ее официальной легализации. Для правильного выбора форм и методов экономической политики противодействия финансированию терроризма необходимо учитывать достижения в области экономической теории. Неправильное формирование экономической политики и ее реализация направляют ресурсы общества по неверному пути, что может привести к затяжным социальноэкономическим потрясениям и росту угроз возникновения экстремистской и террористической деятельности. Например, ошибки руководства Советского Союза в области экономики в конце 80-х годов ХХ столетия привели к крушению государства, усилению националистических движений и вооруженным конфликтам на территории бывшей единой страны. Безусловно, что ошибки в управлении государством являются одними из основных причин разрушения СССР, но далеко не единственными.

В настоящее время принято считать, что экономическая теория делится на позитивную и нормативную экономическую теорию. В первой изучается фактическое состояние экономики, анализируются общепринятые факты, на этой основе делаются обобщения и выводы. Во 
второй исследуется, как должна быть устроена экономика и какая должна проводиться экономическая политика. Например, рассматривая допустимость государственного вмешательства в экономику, желательные нормы оплаты труда, методы пенсионного обеспечения, ставки налогообложения и многое другое, исследователи переходят в область нормативной теории. Именно в этой области экономики имеются большие расхождения в экономических суждениях, выводах и рекомендациях. Как следствие, возникают двойные стандарты. Поэтому не удивительно, что в различных странах могут по-разному оценивать деятельность одних и тех же общественных организаций (объединений), относя их по характеру своей деятельности к либо террористическим, экстремистским, либо к национально-освободительным.

В качестве примера двойных стандартов можно выделить, например, полярные категории: фритредерство и протекционизм. Опыт развитых зарубежных стран показывает, что всякий раз, когда свобода торговли подрывает их экономическую безопасность, страны переходят в той или иной степени к протекционизму. Бездумное следование принципам свободной торговли привело к тому, что Россия потеряла независимость от импорта большого ряда товаров. Все это ограничивает возможности России отстаивать свои национальные интересы, в том числе в сфере борьбы с террористическими организациями. Исходя из указанного, на наш взгляд, необходимо преодолеть догму, в соответствии с которой государство объявлено не эффективным собственником. Полноценных доказательств данного умозаключения нет, а халатная работа государственных и муниципальных служащих, их коррумпированность и не эффективная деятельность получают теоретическое обоснование.

Позитивная экономическая теория менее подвержена двойному толкованию. Но оппортунистическое поведение субъектов рынка может приводить и в данном случае к использованию двойных стандартов, возникающих по причине построения мошеннических схем и меркантильных действий. Тем самым экономическая теория из объективной экономической науки может превратиться в средство проталкивания узкокорыстных интересов. При этом следует учитывать, что невозможна простая экстраполяция в реальную жизнь теорем, аксиом, теоретических формул и графиков, широко представленных в зарубежных и многих отечественных учебниках по экономической теории, для выработки правильной экономической политики.

Развернувшаяся в развитых странах мира цифровизация экономики таит в себе как возможности для развития общества, так и угрозы, в том числе в сфере противодействия финансированию терроризма. С одной стороны, следует констатировать, что новая научно-техническая революция позволяет повысить производительность труда на 30\% [5]. Ожидается, что уже в обозримом времени искусственный интеллект приблизится к человеческому, а в не столь отдаленном будущем интеллектуальные возможности машин начнут соответствовать человеческим и по многим параметрам станут их превосходить.

На ряду с положительными результатами развития искусственного интеллекта следует отметить то, что он формирует большую угрозу для развития всего человечества за счет увеличения численности безработных и обострения на этой основе социально-экономических проблем, так как ухудшение социально-экономического состояния хотя бы части населения является питательной средой для возникновения радикальных экстремистских взглядов, обострения межнациональных отношений и вовлечения отдельных граждан в ряды террористических организаций.

В России рынок искусственного интеллекта в настоящее время находится лишь на начальном этапе своего развития, что во многом обусловлено отсутствием технологической базы для подготовки отечественных кадров в сфере искусственного интеллекта и дефицитом, выделяемых на его развитие финансовых средств. Следует особо отметить, что если в России не будут осуществляться значительные инвестиции в сферу искусственного интеллекта, то возникнет реальная угроза скатывания страны на периферию мирового рынка и превращения ее в лучшем случае в сырьевой придаток высокоразвитых стран. Такой сценарий развития событий обострит социально-экономическую ситуацию в стране, увеличит и без того значительную дифференциацию населения в области доходов, послужит питательной почвой для роста межнациональных конфликтов и, самое негативное, начнет мотивировать часть экстремистски настроенных людей к террористической деятель- 
ности.

В настоящее время в России наблюдается отставание во многих сферах телекоммуникационных технологий. В результате контроль над информацией может перейти к потенциальному противнику и к тем крупнейшим иностранным участникам рынка, которые используют методы промышленного шпионажа и склонны к оппортунистическому поведению. Технические возможности для перехвата информации разнообразны и могут включать в себя даже простой USB-переходник, а перечисление применяемого в этих целях всего арсенала АНБ США занимает 48 страниц машинописного текста [6]. Но наибольшую опасность таит в себе угроза освоения технологий искусственного интеллекта террористическими организациями, что может реализоваться путем коррупционного разложения органов государственной власти, должностных лиц коммерческих организаций [7]. О том, что это потенциально возможно свидетельствуют факты преступных посягательств на программное обеспечение и компьютерные сети. Например, в 2016 г. было зарегистрировано 66 тыс. IT-преступлений, а выявленный ущерб от указанных преступлений за первую половину 2017 г. превысил 18 млн. долл. [8].

Искусственный интеллект, совершенствуя систему финансовых платежей посредством технологии блокчейн, в то же время порождает разнообразные криптовалюты и тем самым расширяет новые горизонты для развития криминальной экономики и, тем самым, открывает новые возможности для финансирования терроризма. Деятельность террористических организаций предполагает скрытость совершаемых ими финансовых операций, что объясняет интерес к использованию в расчетах криптовалют. Основными критериями выбора криптовалюты и криптовалютного кошелька вне зависимости от целей любого пользователя являются надежность и безопасность, но в криминальной экономике главным критерием при их выборе является анонимность. Именно анонимность криптовалют не позволяет оперативно раскрывать и тщательно проводить расследование совершенных и планируемых преступлений. Поэтому террористические организации и другие криминальные структуры выбирают наиболее анонимные криптовалюты и криптовалютные кошельки [9]. Идентификация владельцев криптовалют либо затруднена, либо невозможна, а это разрушает систему контроля за доходами и имуществом должностных лиц государственных и муниципальных органов власти, осложняет противодействие финансированию экстремистских и террористических организаций.

В настоящее время наиболее распространенной криптовалютой по-прежнему является биткоин, но большинство пользователей даркнета предпочитают другие, более анонимные криптовалюты. В настоящее время самой анонимной и защищенной среди них выделяется Monero, использование которой не позволяет узнать, кто является субъектом преступлений террористической направленности. Таким образом, можно сделать вывод о том, что искусственный интеллект, порождая анонимные и защищенные криптовалюты, не позволяет государству проводить полноценную и эффективную запретительную экономическую политику противодействия финансированию терроризма.

\section{Библиографический список}

1. В Совбезе перечислили основные угрозы национальной безопасности России [Электронный ресурс].- Режим доступа: https://centrasia.kz/ru/post/view?id=6048 (дата обращения: 14.07.2019 г.).

2. Чернов С.Б. Противодействие финансированию терроризма: монография / С.Б. Чернов; Государственный университет управления.-М.: Издательский дом ГУУ, 2018.-128 с.

3. Федеральный закон от 07.08.2001 N115-Ф3 (ред. от 03.07.2019) «О противодействии легализации (отмыванию) доходов, полученных преступным путем, и финансированию терроризма»

4. Федеральный закон от 06.03.2006 N35-Ф3 (ред. от 18.04.2018, с изм. от 29.03.2019) «О противодействии терроризму».

5. Искусственный интеллект (ИИ) / Artificial Intelligence (AI) как ключевой фактор цифровизации глобальной экономики [Электронный ресурс].- Режим доступа: https://www.crn.ru/news/detail.php? ID=117544 (дата обращения: 24.02.2017).

6. Нужны ли России свои процессоры и мобильные телефоны [Электронный ресурс].- Режим доступа: https:// texnomaniya.ru/electronics/nuzhni-li-rossii-svoi-processori-i-mobilnie-telefoni.html. (дата обращения: 07.02.2014 г.). 
7. Чернов С.Б. Криптовалюта как угроза государственному и муниципальному управлению // Шаг в будущее: искусственный интеллект и цифровая экономика [Текст]: материалы II Международного научного форума. Вып. 5 / Государственный университет управления.-М.: Издательский дом ГУУ, 2018, с. 349-354.

8. Данные Прокуратуры РФ [Электронный ресурс].- Режим доступа: http://www.tadviser.ru/index.php/Cтатья: Киберпреступность_и_киберконфликты_:_Россия\#.D0.94.D0.B0.D0.BD.D0.BD.D1.8B.D0.B5_D0.9F.D1.80. D0.BE.D0.BA.D1.83.D1.80.D0.B0.D1.82.D1.83.D1.80.D1.8B_D0.A0.D0.A4 (дата обращения: 30.11.2017).

9. Чернов С.Б. Основные угрозы и негативные последствия развития рынка искусственного интеллекта в Российской Федерации. // Шаг в будущее: искусственный интеллект и цифровая экономика [Текст]: материалы 1-й Международной научно-практической конференции. Вып. 4 / Государственный университет управления.- М.: Издательский дом ГУУ, 2017., с. 261-267. 